Post-print version of the paper by Bårdsgjerde et al. in J Adv Nurs. 2019;00:1-11 . https://doi.org/10.1111/jan13931

\title{
Patients' narratives of their patient participation in the myocardial infarction pathway
}

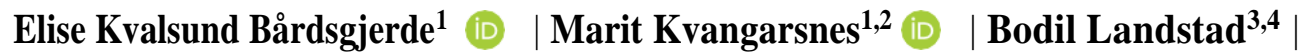

Magne Nylenna ${ }^{5,6}$ | Torstein Hole T,8 $^{7,2}$

${ }^{1}$ Department of Health Sciences in Ålesund, Faculty of Medicine and Health Sciences, Norwegian

University of Science and Technology (NTNU), Ålesund, Norway

2Møre og Romsdal Hospital Trust, Ålesund, Norway

${ }^{3}$ Department of Health Sciences, Mid Sweden University, Sundsvall, Sweden

${ }^{4}$ Levanger Hospital, Nord-Trøndelag Hospital Trust, Levanger, Norway

5Institute of Health and Society, University of Oslo, Oslo, Norway

${ }^{6}$ Norwegian Institute of Public Health, Oslo, Norway

${ }^{7}$ Clinic of Medicine and Rehabilitation, Møre og Romsdal Hospital Trust, Ålesund, Norway

${ }^{8}$ Faculty of Medicine and Health Sciences, Norwegian University of Science and Technology (NTNU), Trondheim, Norway

\section{Correspondence}

Elise Kvalsund Bårdsgjerde, Department of Health Sciences in Ålesund, Norwegian University of Science and Technology (NTNU), Ålesund, Norway.

Email: elise.k.bardsgjerde@ntnu.no

\section{Funding information}

This research was founded by Møre and Romsdal county 
Post-print version of the paper by Bårdsgjerde et al. in J Adv Nurs. 2019;00:1-11 . https://doi.org/10.1111/jan13931

\begin{abstract}
Aim: To explore how patients in areas without local percutaneous coronary intervention (PCI) facilities experience patient participation in different phases of the myocardial infarction pathway.

Background: Acute treatment of myocardial infarction often involves PCI. In Norway, this treatment is centralized at certain hospitals; thus, patients often require long-distance transportation and experience frequent hospital transfers. Short hospital stays, transfers between hospitals and the patient's emotional state pose challenges to promoting patient participation.
\end{abstract}

Design: A qualitative design with a narrative approach.

Methods: Participants were recruited through purposive sampling. Eight men and two women were interviewed in 2016.

Findings: Four themes related to the patients' experiences at the beginning, middle and end of the pathway were identified: (a) Lack of verbal communication in the acute phase; (b) trust in healthcare professionals and treatment; (c) lack of participation and coordination at discharge; and (d) shared decision-making in rehabilitation. The findings showed how the patients moved from a low level of patient participation in the acute phase to a high level of patient participation in the rehabilitation phase.

Conclusion: This is the first study to explore patient participation in different phases of the myocardial infarction pathway. We argue that individual plans for information and patient participation are important to improve patient involvement in an earlier stage of the pathway. Further research from a healthcare professional perspective can be valuable to understand this topic.

Impact: This study gives new insight that can be valuable for healthcare professionals in implementing patient participation throughout the pathway.

\title{
KEYWORDS
}

interview, myocardial infarction, myocardial infarction care, narratives, nursing, patient involvement, patient participation, patient pathway, patient perspective, qualitative 
Post-print version of the paper by Bårdsgjerde et al. in J Adv Nurs. 2019;00:1-11 . https://doi.org/10.1111/jan13931

\section{Why is this research needed?}

- Patient participation in the myocardial infarction pathway is challenging because of acute and often dramatic onset of symptoms, centralized treatment, transfers between hospitals and short hospital stays.

- The perceptions and experiences of patients are important for improving cohesive patient pathways and increasing the quality of health care.

\section{What are the key findings?}

- The patients perceived lack of verbal information and experienced low level of involvement and participation in the acute phase.

- The acute phase is perceived as dramatic because of the transfers between hospitals and the centralized treatment.

- The patients perceived low level of participation in planning the discharge and lack of initiatives about secondary prevention.

\section{How should the findings be used to influence policy/practice/research/education?}

- An individual plan for information would improve patient participation and shared decision-making for patients transferred between different hospitals in the myocardial infarction pathway.

- Before discharge, patients need specific guidance about secondary prevention, which should be standardized and implemented in clinical and educational guidelines. 
Post-print version of the paper by Bårdsgjerde et al. in J Adv Nurs. 2019;00:1-11 . https://doi.org/10.1111/jan13931

\section{INTRODUCTION}

Cardiovascular disease (CVD) remains the leading cause of death worldwide; causing 7.4 million deaths yearly (World Health Organization 2017). Over 12,000 people were diagnosed with myocardial infarction in Norway in 2016 (Grovatsmark, Digre, Sneeggen, Karl-saune, \& Bønaa, 2017). The European Society of Cardiology guidelines for the treatment of acute myocardial infarction (AMI) include thrombolysis and percutaneous coronary intervention (PCI), in addition to standard medical treatment. The pathway consists of different phases. The acute phase starts with the onset of symptoms and until PCI treatment is received. This phase often last only a few hours for patients with ST-segment elevation acute myocardial infarction (STEMI) and up to $72 \mathrm{hr}$ for those diagnosed with non-ST- segment elevation (nSTEMI). The acute phase is followed by the discharge phase and the rehabilitation phase, which often last for several months. According to the ESC guidelines PCI facilities are centralized in many countries with sparse population (Roffi et al., 2016; Task Force on the management of ST segment elevation acute myocardial infarction of the European Society of Cardiology, Steg et al. 2012) and patients from sparsely populated areas are often transferred between hospitals (Chew et al., 2013; Clune, Blackford, \& Murphy, 2014; Hagen, Häkkinen, Belicza, Fatore, \& Goude, 2015; Tanguay, Dallaire, Hébert, Bégin, \& Fleet, 2015). Eight hospitals have PCI facilities in Norway. Because of this centralization of treatment in Norway a significant proportion of the population lives more than $300 \mathrm{~km}$ away from the nearest PCI hospital and are dependent on helicopter or air ambulance to receive treatment in the acute phase. The AMI pathway has four possible options: (a) admitted to and discharged from a PCI hospital; (b) admitted to a PCI hospital and then transferred to and discharged from a local hospital; (c) admitted to a local hospital and then transferred to and discharged from a PCI hospital; and (d) admitted to a local hospital, transferred to a PCI hospital and then transferred back to and discharged from a local hospital (Grovatsmark et al., 2017).

Secondary prevention with lifelong medication and lifestyle changes is crucial to prevent new cardiac events (Piepoli et al., 2016). In most western countries, cardiac rehabilitation programmes are available after discharge, but participation in those programmes is low (Grovatsmark etal., 2017; Kotseva etal., 2016). Guidelines recommend that secondary prevention should be initiated before discharge (Piepoli et al., 2010; Task Force on the management of ST segment elevation acute myocardial infarction of the European Society of Cardiology, Steg etal.2012). Short hospital stays (Piepoli et al., 2016; Townsend, Nichols, Scarborough, \& Rayner, 2015) and transfers between hospitals can reduce the opportunity for patient participation. 
Post-print version of the paper by Bårdsgjerde et al. in J Adv Nurs. 2019;00:1-11 . https://doi.org/10.1111/jan13931

According to Norwegian legislation (Ministry of Health and Care Services 1999), patients have a right to information and participation in all health and care services. Information and information-sharing between healthcare professionals and patients is a key requirement for participation (Angel \& Frederiksen, 2015; Brownlea,1987; Tobiano, Marshall, Bucknall, \& Chaboyer, 2015). Patient participation is a complex phenomenon and no clear definitions exist (Cahill, 1996; Collins, Britten, Ruusuvuori, \& Thompson, 2007; Thompson, 2007). Despite the lack of a clear definition, patient participation is characterized by the following attributes; a relationship must exist between patient and healthcare professionals; there must be a narrowing of the gap in information, knowledge and competence among the parts; a degree of power and control must be handed over from the healthcare professional to the patient; and patient and healthcare professionals must collaborate in activities (Cahill, 1996; Sahlsten, Larsson, Sjöström, \& Plos, 2008). Thompson (2007) emphasized that participation is dependent on context, the patients' desire to participate and reciprocity between patient and healthcare professionals.

In Norway, much attention has recently been placed on the Coordination reform (Report No. 47 (2008-2009) 2008), which focuses on coordination between primary health care and hospitals, with cohesive patient pathways and increased patient involvement as targets. There has been a sparse focus on the coordination between hospitals in regard to cohesive pathways and patient participation. This study explores patient participation in the myocardial infarction pathway.

\section{1 | Background}

Patient participation can improve patient safety and quality in health care (Delnoji \& Hafner, 2013). Patient participation through person- and family-centred care is highlighted internationally and the campaign "what matters to you?" is implemented in many countries (IHI 2018a,b).

Myocardial infarction is often experienced as an unexpected and life-threatening event (Dullaghan et al., 2014; Fors, Dudas, \& Ekman, 2014; Sampson, O'Cathain, \& Goodacre, 2009). Rapid diagnosis and initiation of treatment is prioritized in the acute phase and this often pose challenges to information and patient participation. Studies have shown that patients with myocardial infarction do not wish to participate in the acute phase (Arnetz \& Arnetz, 2009; Decker et al., 2007; Höglund, Winblad, Arnetz, \& Arnetz, 2010; Radcliffe, Harding, Rothman, \& Feder, 2009). Despite this lack of desire to participate, Decker et al. (2007) and Höglund et al. (2010) found that patient appreciated short and clear information in the acute phase. 
Post-print version of the paper by Bårdsgjerde et al. in J Adv Nurs. 2019;00:1-11 . https://doi.org/10.1111/jan13931

Studies have explored patient's experiences with information. Astin, Closs, McLenachan, Hunter, and Priestley (2008) found that most patients were satisfied with the general information but missed tailored and individualized information. Oterhals, Hanestad, Eide, and Hanssen (2006) found that patients received information about smoking habits and the nature and causes of myocardial infarction. Patients have reported to receive less information about medication, lifestyle changes, risks of recurrence and future problems, sexual activity and heart muscle damage (Astin et al., 2008; Oterhals et al., 2006). Several studies have found that a face-to-face dialogue was important for the patients (Astin et al., 2008; Decker et al., 2007; Svavarsdóttir, Sigurdardottir, \& Steinsbekk, 2016). In addition, the information should be honest, consistent and easy to understand (Astin et al., 2008) and the presence and time of the healthcare professionals were valued (Svavarsdóttir et al., 2016). At discharge and early recovery, many patients experienced fear and anxiety (Astin et al., 2008; Fålun, Fridlund, Schaufel, Schei, \& Norekvål, 2016; June- hag, Asplund, \& Svedlund, 2014). Oterhals et al. (2006) and Decker et al. (2007) found that information was especially lacking at this point. Short hospital stays, rapid throughput of patients and the patient's emotional state have been found to be barriers to the patient's ability to absorb information (Astin et al., 2008; SalminenTuomaala, Åstedt-Kurki, Rekiaro, \& Paavilainen, 2012; Svavarsdóttir et al., 2016).

Arnetz and Arnetz (2009) and Decker et al. (2007) found that the patients expressed an increased desire for participation during hospitalization, especially at discharge (Arnetz \& Arnetz, 2009). Barriers to participation often include patient's characteristics and lack of time and resources (Arnetz, Winblad, Arnetz, \& Höglund, 2008; Eldh, Ehnfors, \& Ekman, 2004; Höglund et al., 2010; Larsson, Sahlsten, Sjöström, Lindencrona, \& Plos, 2007; Sahlsten, Larsson, Plos, \& Lindencrona, 2005). Another obstacle for patient participation could be lack of patient-nurse continuity (Eldh et al., 2004; Larsson et al., 2007; Sahlsten et al., 2005).

Studies have explored how patients experience PCI treatment and patients have reported being satisfied with PCI treatment and outcomes (Dullaghan et al., 2014; Radcliffe et al., 2009; Sampson et al., 2009). Patient misunderstanding about the PCI treatment as curative (Astin, Closs, McLenachan, Hunter, \& Priestley, 2009; Sampson et al., 2009) and the condition as acute rather than chronic (Alsén, Brink, \& Persson, 2008; Astin et al., 2009) have been documented. Dullaghan et al. (2014) found that the patients expressed an understanding of the condition as chronic and were therefore motivated to make lifestyle changes. Kähkönen et al. (2015) found that motivation was a key factor for adherence to secondary prevention. These findings highlight the need for patient participation during treatment to enhance the understanding of their condition and their motivation to initiate lifestyle changes. As far as we know, no previous research has systematically explored how patient participation is experienced in different phases of the 
Post-print version of the paper by Bårdsgjerde et al. in J Adv Nurs. 2019;00:1-11 . https://doi.org/10.1111/jan13931

myocardial infarction pathway. We have not found studies exploring how patients experience long travel distances to receive treatment. This study contributes to new knowledge that can improve patient participation in the clinical pathway. The study can give insight from a patient perspective that can be used in education and in further research about patient participation.

We have chosen to use Thompson's (2007) taxonomy as a theoretical framework. Thompson (2007) found that patient involvement and participation occurred at different levels. These levels are as follows: (0) "noninvolvement"; (1) "information-seeking/receptive"; (2) "information giving/dialogue"; (3) "shared decisionmaking"; and (4) "autonomous decision-making". Each of the levels are related to levels of power, where patient power is increasing from no power at level 0 to having full autonomy at level 4 . A high level of involvement and patient power also includes more responsibility for the patients. Participation is based on expectations of reciprocal open and honest relationships, mutual respect and a sharing of information through two-way communication that leads to dialogue. This dialogue underpins the possibility of shared decisionmaking (Thompson, 2007).

\section{2 | THE STUDY}

\section{1 | Aim}

To explore patient participation in the myocardial infarction pathway. The research question was: How do patients in areas without local PCI facilities experience patient participation in different phases of the myocardial infarction pathway?

\section{2 | Design}

A qualitative design using a narrative approach was chosen to investigate the patients' experiences of participation. A personal narrative is a distinct form of communication (Chase, 2018) and is a suitable approach when the goal is to explore the experiences of people during certain life situations (Chase, 2005), for example, a heart attack.

Narrative is coterminous with story and has a beginning, a middle and an ending. The narrative has a temporal dimension and is held together by a recognizable pattern of events that represent the plots (Sarbin, 1986). 
Post-print version of the paper by Bårdsgjerde et al. in J Adv Nurs. 2019;00:1-11 . https://doi.org/10.1111/jan13931

\subsection{Sample}

The participants were recruited through purposive sampling (Polit \& Beck, 2012). Men and women from different ages and backgrounds were included to increase diversity. The inclusion criteria were patients who were: (a) diagnosed with AMI; (b) living in areas more than $300 \mathrm{~km}$ away from a PCI hospital; (c) transported by helicopter/air ambulance in the acute phase; (d) not suffering from other serious illnesses; and (e) able to give informed consent. Healthcare professionals working at two different cardiac rehabilitation units invited patients, that met the inclusion criteria, face-to-face to attend in the study. Sixteen patients were invited, six did not wish to attend and no reason for not attending was given. Two women and eight men between 37-79 years participated in the study. Demographic data are listed in Table 1.

TABL E 1 Demographic data and pathways

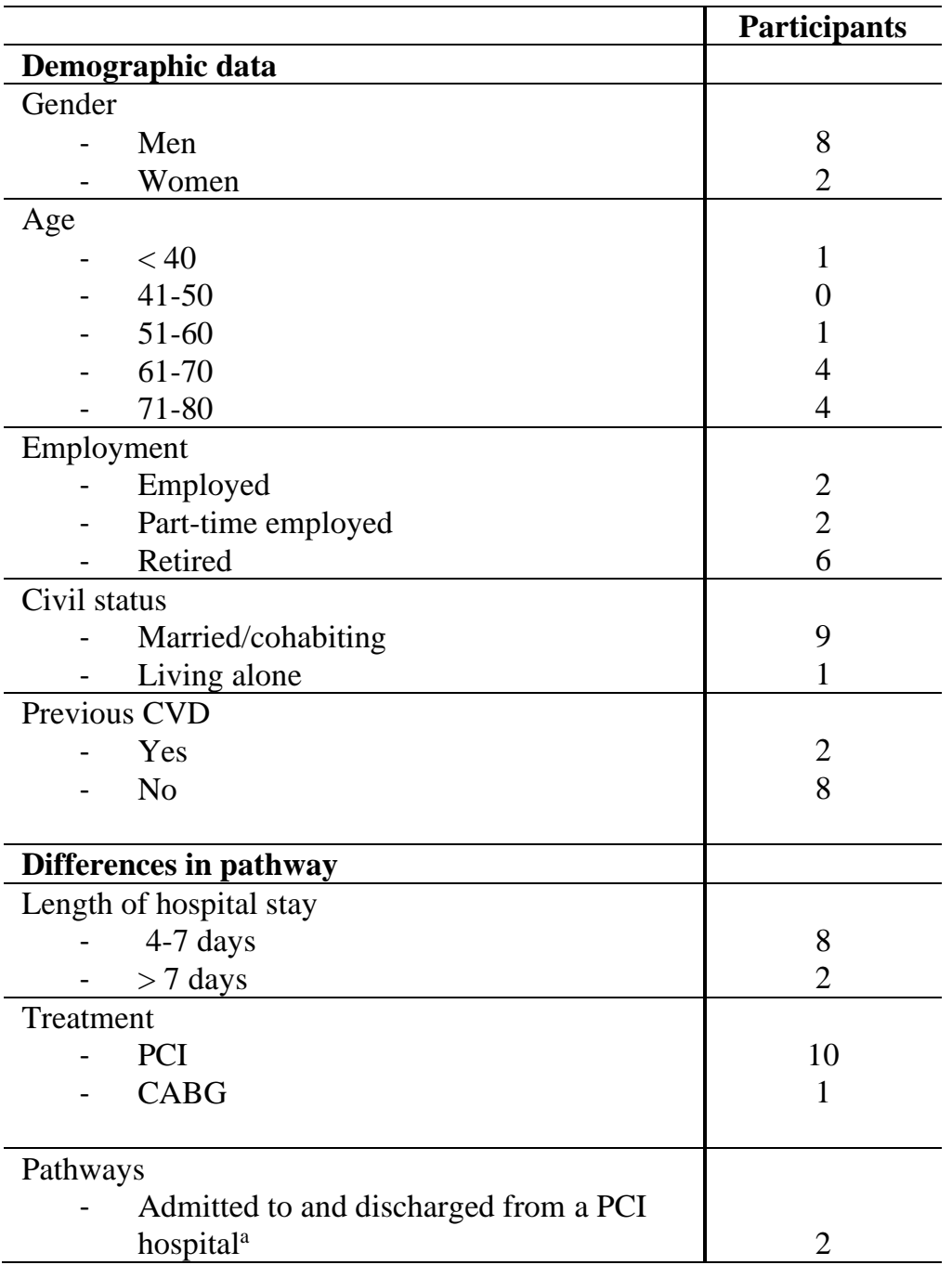


Post-print version of the paper by Bårdsgjerde et al. in J Adv Nurs. 2019;00:1-11 . https://doi.org/10.1111/jan13931

\begin{tabular}{|c|c|c|}
\hline - & $\begin{array}{l}\text { Admitted to a PCI hospital and then } \\
\text { transferred to and discharged from a local } \\
\text { hospital } \\
\text { Admitted to a local hospital and then } \\
\text { transferred to and discharged from a PCI } \\
\text { hospital } \\
\text { Admitted to a local hospital, transferred to } \\
\text { a PCI hospital and then transferred back } \\
\text { and discharged from a local hospital }\end{array}$ & 1 \\
\hline Regic & $\begin{array}{l}\text { Thealth trusts } \\
\text { Treated in the regional health trust they } \\
\text { geographically belonged to } \\
\text { Treated in another geographical regional } \\
\text { health trust than the one they belonged to }\end{array}$ & 7 \\
\hline
\end{tabular}

Note. PCI, percutaneous coronary intervention; $\mathrm{CABG}$, coronary artery bypass grafting.

${ }^{\mathrm{a}}$ Hospital with percutaneous coronary intervention facilities.

\subsection{Data collection}

An interview guide (Kvale \& Brinkmann, 2009) was developed based on the aim of the study, previous research, the theory of narrative inquiry (Chase, 2005) and participation (Thompson, 2007). Open- ended questions (Table 2) were used and the participants told their stories mostly uninterrupted (Chase, 2005). The guide was not used in a rigid way and follow-up questions were asked when needed. Ten interviews were conducted in January and February of 2016. The interviews were carried out 2-5 months after the myocardial infarction event in an office at the cardiac rehabilitation unit at two local hospitals. Only the participant and the interviewer (the first author) were present during the interview. The interviews lasted between 38 and $128 \mathrm{~min}$. The interviews were audio recorded and transcribed verbatim by the first author. Data saturation was discussed throughout the process of interviewing and in the first phase of analysis. After 10 interviews, the data were rich and diverse (Chase, 2005; Grbich, 2012) and became repetitive and redundant (Polit \& Beck, 2012); therefore, the data were considered to be saturated.

TABL E 2 Interview guide

Can you tell me how you experienced having a myocardial infarction?

How did you experience the information you received in different phases of the pathway (e.g., acute phase, discharge phase, rehabilitation phase)?

How did you experience participating in the different phases of the pathway (e.g., acute phase, discharge phase, rehabilitation phase)? 
Post-print version of the paper by Bårdsgjerde et al. in J Adv Nurs. 2019;00:1-11 . https://doi.org/10.1111/jan13931

\subsection{Ethical considerations}

An application was submitted to the Regional Committee for Medical and Health Research Ethics (REK Mid-Norway 2015/2002), which concluded that the study did not need their approval. The Norwegian Centre for Research Data approved the study (project number 56617). During the interviews, the interviewer was aware of the participants' possible emotional reactions to an acute and life-threatening event. Healthcare professionals were available if medical help was needed. Informed consent based on oral and written information was obtained prior to data collection. The participants were informed that they could withdraw from the study at any point.

\section{6 | Data analysis}

In the analysis, the five analytic lenses described by Chase (2005) were used. First, each narrative was read focusing on what the story was about and how it was told (lense 1 and 2). Then, we looked for diversity and similar patterns among the narratives (lense 3). The participants' experiences were related to the different phases in the pathway, the acute phase, the discharge phase and the rehabilitation phase. The data were coded based on the described phases (lense 4 and 5) and in the process of coding we used Thompson's (2007) levels of involvement and participation. Furthermore, the codes were used to construct the plot consisting of recognizable patterns of events in the narratives (Sarbin, 1986). Finally, the 10 interviews were compiled and reconstructed into one story (Kvale \& Brinkmann, 2009) consisting of four themes following the beginning, the middle and the end of the narratives. Table 3 shows how one of the themes was developed.

TABL E 3 Development from quotes to theme

\begin{tabular}{|l|l|l|}
\hline Quotes & Patterns & Theme \\
\hline $\begin{array}{l}\text { "I did not get any warning" } \\
\text { "I did not believe it was a myocardial infarction, because I did not } \\
\text { have so much pain" }\end{array}$ & $\begin{array}{l}\text { Sudden onset } \\
\text { and diffuse } \\
\text { symptoms }\end{array}$ & \\
and gone to rest" & $\begin{array}{l}\text { Lad not had it before, maybe I would have thought I was tired } \\
\text { "They told me that it was a myocardial infarction and they gave me } \\
\text { nome medicine directly in my blood vessels. If the medication did } \\
\text { "They did not say anything. Except the chief physician saying you } \\
\begin{array}{l}\text { will be transferred immediately" } \\
\text { "No one said anything before we were at the heliport, waiting for } \\
\text { the elevator. Then, the physician from the helicopter touched my } \\
\text { shoulder and said, "now you are safe"” }\end{array}\end{array}$ & $\begin{array}{l}\text { Lack } \\
\text { communication in } \\
\text { the acute phase }\end{array}$ \\
$\begin{array}{l}\text { "The physician put on the ECG electrodes, and probably he saw } \\
\text { that I had an ongoing myocardial infarction. Then, he called for an }\end{array}$ & $\begin{array}{l}\text { Getting } \\
\text { information }\end{array}$ & \\
\hline
\end{tabular}


Post-print version of the paper by Bårdsgjerde et al. in J Adv Nurs. 2019;00:1-11 . https://doi.org/10.1111/jan13931

ambulance, and I heard them discussing back and forth" "I did understand that it was critical when they needed our defibrillator [from his workplace]. They were relieved that we had one nearby, so they did not have to go back to the ambulance to pick up their own"

through
interpretation
of healthcare
professionals'
actions and
interactions

\section{7 | Rigour}

Credibility was enhanced through explicit description of the study and being as transparent as possible. A member check at the end of each interview was performed and quotations are used to increase credibility (Lincoln \& Guba, 1985). The first author, under the guidance of the second author, performed the analysis. To achieve confirmability (Lincoln \& Guba, 1985), two of the other authors also read the transcripts and all four discussed the findings. The last author had specific clinical experience with the myocardial infarction pathway. To increase transferability, the findings are presented through rich descriptions (Lincoln \& Guba, 1985).

\section{3 | FINDINGS}

The findings showed how 10 patients, age 37-79 years old, experienced participation in the myocardial infarction pathway. Four themes related to the phases in the pathway were constructed: (a) lack of verbal communication in the acute phase; (b) trust in healthcare professionals and treatment; (c) lack of participation and coordination at discharge; and (d) shared decision-making in rehabilitation.

\subsection{Lack of verbal communication in the acute phase}

In the acute phase, the patients explained how they tried to understand the situation. Most of the patients experienced a sudden onset of symptoms. A repeated phrase in the data was "I did not get any warning". In addition, the symptoms could be diffuse. Except the two patients who had previous CVDs, few of the patients understood that their symptoms were caused by a myocardial infarction. One patient said, "I did not believe it was a myocardial infarction, because I did not have so much pain" (Informant J, male). One patient with a previous CVD said, "If I had not had it before, maybe I would have thought I was tired and 
Post-print version of the paper by Bårdsgjerde et al. in J Adv Nurs. 2019;00:1-11 . https://doi.org/10.1111/jan13931

gone to rest" (Informant $F$, male).

Some of the patients received information that included their diagnosis and a brief treatment plan. One patient described it as follows: "They told me that it was a myocardial infarction and they gave me some medicine directly in my blood vessels. If the medication did not work, I would be transferred" (Informant $G$, male). Most of the patients received little verbal information, as stated by one patient: "They did not say anything. Except the chief physician saying; you will be transferred immediately" (Informant D, male). Another patient said, "No one said anything before we were at the heliport, waiting for the elevator. Then, the physician from the helicopter touched my shoulder and said; "now you are safe"” (Informant H, male).

The patients reported how they interpreted the healthcare professional's actions and interactions due to the shortage of information. One patient described it as follows: "The physician put on the ECG electrodes and probably he saw that I had an ongoing myocardial infarction. Then, he called for an ambulance and I heard them discussing back and forth" (Informant B, female). Another patienthad a traumatic experience when a defibrillator was prepared and described it as follows: "I did understand that it was critical when they needed our defibrillator [from his workplace]. They were relieved that we had one nearby, so they did not have to go back to the ambulance to pick up their own" (Informant H, male).

\section{2 $\quad$ Trust in healthcare professionals and treatment}

In the treatment phase, the patients revealed that they trusted the healthcare professionals and were confident with the treatment they received. Several of the patients used the phrase "to be in safe hands" to describe their experiences. They described the healthcare professionals as highly qualified, calm and knowledgeable about what to do in the situation and reported that medical decisions were made quickly. The following quote illustrates one patient's experience: "Even if it was intense situations in the beginning, the people were calm and said what was necessary to say. I think that the way you are met is important in these situations, that they are calm and show that they have control" (Informant $G$, male). In the acute phase, the patients appreciated having their next of kin with them. However, after the PCI treatment, they did not think that it was necessary.

Some of the patients reported that their impression of the PCI procedure was that it was something ordinary. One patient described it as follows: "It seemed like it was something that they had done several times before and that it actually was not a severe intervention" (Informant G, male). Another patient said, "A treatment like this, if it works, is simple"(Informant E, male). 
Post-print version of the paper by Bårdsgjerde et al. in J Adv Nurs. 2019;00:1-11 . https://doi.org/10.1111/jan13931

The patients reported that they received tailored information about the treatment and outcome during or immediately after the PCI procedure. One patient described it as follows: "I did not feel anything during the procedure. At 03.20 in the night the cardiologist was done and said; 'this went well, now you can go home"" (Informant I, male). Some of the patients also watched the screen during the procedure and spoke vividly about it: "I saw the little thing [wire] and felt how it tickled upwards my arm. They told me; 'look at the screen, there he [the wire] is coming out and there it is, your myocardial infarction'. Next to the myocardial infarction, you could see the normal heart beating" (Informant D, male).

\subsection{Lack of participation and coordination at discharge}

The patients reported receiving a varying amount of information about lifestyle changes, further medical treatment and rehabilitation. Some of the patients were satisfied and had received both oral and written information. One patient described the written information as an instruction book: "If I wonder about something I just look in the folder. It is written in simple sentences that are easy to understand" (Informant A, male).

Others would have preferred tailored and concrete information on how to initiate lifestyle changes in their everyday life. One patient described it as follows: "If you could receive simple diet advices at the hospital, for example, reduce the use of milk products and choose oils instead of butter, then you could start make changes already at discharge" (Informant B, female). Medication was another topic where the patients reported receiving poor information, especially about effects and side effects. Some also repeatedly talked about their medication and wondered how long they needed them for and if they could reduce some of the medications after a while. About physical activity, the patients wanted the information to be as specific as possible. One patient reported that he received a recipe: "Tomorrow you can start walking $500 \mathrm{~m}$ on flat road and then you can gradually increase the distance and accelerate" (Informant E, male).

Several of the patients stated that they worried about discharge, especially the journey home from the PCI hospital. All of the patients were treated at hospitals more than $300 \mathrm{~km}$ away from where they lived, and their journey home could include several bus lines, planes and ferries. The patients lacked personal belongings; that is, clothes, money, credit cards and mobile charger. As described by one patient, "I only had a sweat suit and my mobile" (Informant D, male).

Patients treated at a regional health trust other than the one they geographically belonged to became responsible for both the arrangement and cost of their journey home. One of these patients used the metaphor 
Post-print version of the paper by Bårdsgjerde et al. in J Adv Nurs. 2019;00:1-11 . https://doi.org/10.1111/jan13931

"being promised the moon" when the healthcare professionals first promised him that he would be transferred home by air ambulance. Then, the next day, he was told that it was too expensive and not the hospital's responsibility because of the geographical borders.

The patients who were transferred back to the local hospital by air ambulance described relief: "I was a bit worried about how I should return home. I was relieved when they told me that I would be transported by air ambulance"(Informant $C$, female).

\section{4 | Shared decision-making in rehabilitation}

All of the patients participated in an outpatient cardiac rehabilitation programme lasting 3-4 months at their local hospital. Those who were transferred back to their local hospital initiated contact with the staff from the rehabilitation programme before discharge through a ward visit.

All the patients described the cardiac rehabilitation programme with positive phrases; one patient expressed, "To start here is the best thing ever happened to me" (Informant I, male). Through the programme, they not only received information but also increased their knowledge and understanding of the coherence between disease and lifestyle. One patient described it as follows: "I have received most information through this course, they have told us about the heart's physiology and its function, diets and exercise" (Informant $C$, female).

The patients reported that the follow-up from the staff was good and appreciated the opportunity to test themselves physically in a safe environment. One patient said the following: "After I started the training I knew that I [my body] tolerate a lot" (Informant B, female). Through the programme, they also met

other patients and they described this interaction to be motivating. One statement was as follows: "Among fellows you can talk about problems and discuss challenges together" (Informant $F$, male). They stated how both their motivation and responsibility for their own health were increased throughout the programme. One patient described it as follows: "I will never have another myocardial infarction. I know you cannot choose that, but I will do my very best to prevent another one" (Informant H, male).

Some of the patients reflected on the time aspect, stating that it was easier to gain new information during the rehabilitation programme rather than at the hospital. One patient reflected on this as follows: "One of the good things at the cardiac rehabilitation is the distance to the acute event. If they had told me much more at the hospital I do not know if I could have grasped it" (Informant $C$, female). 
Post-print version of the paper by Bårdsgjerde et al. in J Adv Nurs. 2019;00:1-11 . https://doi.org/10.1111/jan13931

\section{DISCUSSION}

In this qualitative study, we aimed to explore how patients living in areas without local PCI facilities experience patient participation in the myocardial infarction pathway. We identified that participants moved from a low level of patient participation in the acute phase to a high level of patient participation in the rehabilitation phase.

In our study, the participants had a passive role in the acute phase and there was a lack of verbal communication between the participants and healthcare professionals. Passive patient participation in the acute phase of a myocardial infarction has also been identified by other researchers (Arnetz \& Arnetz, 2009; Decker et al., 2007; Höglund et al., 2010; Radcliffe et al., 2009) and Thompson (2007) also claims that patient participation is less important in acute phases of illness. A notable finding in our study was the way the participants were able to accurately recall what had happened to them during the acute phase of their myocardial infarction and discussed in detail the healthcare professionals' actions and conversations. In the most dramatic situations, this could be frightening for some of them, for example, the participant who experienced the defibrillator being prepared without receiving any verbal information. Previous studies have found that clear information is important in this phase (Decker et al., 2007; Höglund et al., 2010).

We identified that participants trusted the healthcare professionals and the treatment they received. Trust can be a coping strategy to situations with high levels of fear and anxiety (Thompson, 2007). Trust can also be connected to a lack of understanding of the severe situation, as described by other researchers (Alsén et al., 2008; Astin et al., 2009; Sampson et al., 2009). Some of the participants in our study reported that the procedure was described as a routine intervention, which might have an impact on how they understand the severity of their situation. The participants reported that information about treatment and outcome was given during or immediately after the procedure. Through their stories, it seemed like this was a one-way communication from the cardiologist to the participant, without dialogue between the parts. This is described by Thompson (2007) as level 1 of involvement, where the patient is information-seeking. An explanation could be that the participants' abilities to advance to a dialogue may be reduced right after the acute event.

The narratives revealed a difference among the participants about secondary prevention and some participants described a lack of guidance on how they should initiate lifestyle changes in their everyday life. This lack of specific and tailored information has also been reported in other studies (Arnetz \& Arnetz, 2009; Astin et al., 2008; Oterhals et al., 2006). It is of concern that despite international guidelines (Task 
Post-print version of the paper by Bårdsgjerde et al. in J Adv Nurs. 2019;00:1-11 . https://doi.org/10.1111/jan13931

Force on the management of ST segment elevation acute myocardial infarction of the European Society of Cardiology, Steg et al. 2012) highlighting the importance of initiating lifestyle changes before discharge, patients still lack information and guidance. Some of the participants were transferred between different hospitals, which may have affected the continuity in care, as other studies have found that nurse-patient continuity is an important precondition for patient participation (Eldh etal., 2004; Larsson et al., 2007; Sahlsten et al., 2005). Another explanation for the variation in the amount of information could be due to differences between the hospitals. Some of the participants were treated only at hospitals with PCI facilities and not at their local hospital. PCI hospitals may have a focus on giving highly technical treatment and may have a higher turnover rate with a rapid throughput of patients. Meanwhile, local hospitals may focus more on rehabilitation through follow-up treatment and secondary prevention. Another explanation could be the participant's ability to absorb both the severe situation and information. These challenges have been described in previous research (Astin et al., 2008; Salminen-Tuomaala et al., 2012; Svavarsdóttir et al., 2016). Lack of time and resources have also been found in previous studies to be barriers to patient participation (Arnetz et al., 2008; Eldh et al., 2004; Höglund et al., 2010; Larsson et al., 2007; Sahlsten et al., 2005). Previous research indicate that the patients' understanding of the condition, as acute or chronic, might have an impact on patient motivation (Alsén et al., 2008; Astin et al., 2009; Dullaghan et al., 2014; Sampson et al., 2009). Thompson (2007) also emphasize that patient participation is easier to achieve in chronic conditions.

Some of the participants described a vulnerable situation in the discharge process, especially discharge from the PCI hospital. The participants lacked personal belongings, such as clothes, money and credit cards, which are needed to travel by public transportation. This finding is also supported by Valaker et al. (2017), who also found that transportation was inadequately planned for patients who had to travel long distances.

In the present study, all of the participants attended an outpatient cardiac rehabilitation programme and they highlighted how valuable the programme had been to them. The participants spoke of the rehabilitation programme as a turning point at which they started to take an active role in their treatment and became motivated to initiate lifestyle changes. The setting at the rehabilitation programme, with continuity over time, seems to improve the preconditions for increasing knowledge and understanding. This finding is in accordance with Thompson's (2007) theory that a reciprocal and mutual relationship must be established between the patient and the healthcare professionals as a precondition for patient participation. It is of concern how important the rehabilitation programme was for the participants when previous studies have found that participation in outpatient cardiac rehabilitation programmes is low (Grovatsmark et al., 2017; Kotseva et al., 2016). The 
Post-print version of the paper by Bårdsgjerde et al. in J Adv Nurs. 2019;00:1-11 . https://doi.org/10.1111/jan13931

reasons for not attending outpatient cardiac rehabilitation programmes appear to be multifactorial, including age, female sex and travel distance to the outpatient cardiac rehabilitation centre (Jelinek, Thompson, Ski, Bunker, \& Vale, 2015; Ruano-Ravina et al., 2016; Shimada \& Scirica, 2015). In our study, healthcare professionals from the cardiac rehabilitation programme visited some of the participants at the ward, which might have a positive impact on their motivation and may increase participation in the rehabilitation programmes.

Our study findings suggest that patients progressed from passive to active participants, following a continuum of levels of patient participation as explained by Thompson (2007). This finding is also supported by Eldh et al. (2004), who found that patients did not expect to participate in the acute care setting but wanted to participate later during the treatment.

\section{1 | Limitations}

Thompson's taxonomy was published in 2007. We are aware of that research on patient participation at both individual and system levels have developed the last 10 years (Vahdat, Hamzehgardeshi, Hessam, \& Hamzehgardeshi, 2014). Therefore, Thompson's (2007) taxonomy can be considered as outdated. However, the taxonomy contributes to an understanding of patient participation as dynamic and contextual, which makes it appropriate to study patient participation in the clinical pathway.

At the time of the study, 2-5 months had passed since the participants were discharged from the hospital. This can be a long time regarding memory, but the elapsed time could also be a benefit emotionally by giving some distance from the AMI event. Only two women participated, but the aim was not to explore different perceptions between women and men.

\section{5 | CONCLUSION}

This is the first study to explore patient participation in different phases of the myocardial infarction pathway. We have identified that participants progressed from a low level of involvement in the acute phase to shared decision-making in the rehabilitation phase. We argue that individual plans for information and patient participation are important to improve patient involvement in an earlier stage of the pathway. Further research from a healthcare professional perspective can be valuable to understand this topic. 
Post-print version of the paper by Bårdsgjerde et al. in J Adv Nurs. 2019;00:1-11 . https://doi.org/10.1111/jan13931

\section{AUTHOR CONTRIBUTIONS}

All authors have agreed on the final version and meet at least one of the following criteria (recommended by the ICMJE [http://www.ic mje.org/recommendations/]):

- substantial contributions to conception and design, acquisition of data, or analysis and interpretation of data;

- drafting the article or revising it critically for important intellectual content.

\section{ACKNOWLEDGEMENTS}

We want to thank the participants for sharing their valuable experiences, and the healthcare professionals who recruited participants to the study.

\section{CONFLICTS OF INTEREST}

No conflict of interest has been declared by the authors.

\section{ORCID}

Elise Kvalsund Bårdsgjerde (D) https://orcid.org/0000-0001-5182- 0840

Marit Kvangarsnes (D) https://orcid.org/0000-0002-9923-0177

\section{REFERENCES}

Alsén, P., Brink, E., \& Persson, L. O. (2008). Patients' illness perception four months after a myocardial infarction. Journal of Clinical Nursing, 17(5a), 25-33. https://doi.org/10.1111/j.1365-2702.2007. 02136.x

Angel, S., \& Frederiksen, K. N. (2015). Challenges in achieving patient participation: A review of how patient participation is addressed in empirical studies. International Journal of Nursing Studies, 52(9), 1525- 
Post-print version of the paper by Bårdsgjerde et al. in J Adv Nurs. 2019;00:1-11 . https://doi.org/10.1111/jan13931

1538. https://doi.org/10.1016/j.ijnurstu.2015.04.008

Arnetz, J. E., \& Arnetz, B. B. (2009). Gender differences in patient perceptions of involvement in myocardial infarction care. European Journal of Cardiovascular Nursing, 8(3), 174-181. https://doi.org/ 10.1016/j.ejcnurse.2008.11.002

Arnetz, J. E., Winblad, U., Arnetz, B. B., \& Höglund, A. T. (2008). Physicians' and nurses’ perceptions of patient involvement in myocardial infarction care. European Journal of Cardiovascular Nursing, 7(2), 113-120.https://doi.org/10.1016/j.ejcnurse.2007.05.005

Astin, F., Closs, S. J., McLenachan, J., Hunter, S., \& Priestley, C.

(2008). The information needs of patients treated with primary angioplasty for heart attack: An exploratory study. Patient Education and Counseling, 73(2), 325-332. https://doi.org/10.1016/j.pec. 2008.06.013

Astin, F., Closs, S. J., McLenachan, J., Hunter, S., \& Priestley, C. (2009). Primary angioplasty for heart attack: Mismatch between expectations and reality? Journal of Advanced Nursing, 65(1), 72-83. https://doi. org/10.1111/j.1365-2648.2008.04836.x

Brownlea, A. (1987). Participation: Myths, realities and prognosis. Social Science \& Medicine, 25(6), 605-614. https://doi.org/10.1016/02779536(87)90085-2

Cahill, J. (1996). Patient participation: A concept analysis. Journal of Advanced Nursing, 24(3), 561-571. https://doi.org/10.1046/j.1365- 2648.1996.22517.x

Chase, S. E. (2005). Narrative inquiry multiple lenses, approaches, voices. In N. K. Denzin \& Y. S. Lincoln (Eds.), The Sage handbook of qualitative research (pp. 651-679). Thousand Oaks, CA: Sage.

Chase, S. E. (2018). Narrative inquiry toward theoretical and methodological maturity. In N. K. Denzin \& Y. S. Lincoln (Eds.), The Sage handbook of qualitative research. Los Angeles, CA: Sage.

Chew, D. P., French, J., Briffa, T. G., Hammett, C. J., Ellis, C. J., Ranasinghe, I., ...Lefkovits, J. (2013). Acute coronary syndrome care across Australia and New Zealand: The SNAPSHOT ACS study. The Medical Journal of Australia, 199(3), 185-191. https://doi.org/10.5694/mja12.11854

Clune, S. J., Blackford, J., \& Murphy, M. (2014). Management of the acute cardiac patient in the Australian rural setting: A 12 month retrospective study. Australian Critical Care, 27(1), 11-16. https:// doi.org/10.1016/j.aucc.2013.03.002

Collins, S., Britten, N., Ruusuvuori, J., \& Thompson, A. (2007). Understanding the process of patient participation. In S. Collins, N. Britten, J. Ruusuvuori, \& A. Thompson (Eds.), Patient participation in 
Post-print version of the paper by Bårdsgjerde et al. in J Adv Nurs. 2019;00:1-11 . https://doi.org/10.1111/jan13931

health care consultations qualitative perspectives (pp.3-21). Maidenhead, UK: Open University Press.

Decker, C., Garavalia, L., Chen, C., Buchanan, D. M., Nugent, K., Shipman, A., \& Spertus, J. A. (2007). Acute myocardial infarction patients' information needs over the course of treatment and recovery. Journal of Cardiovascular Nursing, 22(6), 459-465. https://doi.org/10.1097/01. JCN.0000297391.11324.0f

Delnoji, D., \& Hafner, V. (Eds.) (2013). Exploring patient participation in reducing health-care-related safety risks. Europe: World Health Organization. Retrieved from http://www.euro.who.int/ data/assets/pdf_file/0010/185779/e96814.pdf?ua=1

Dullaghan, L., Lusk, L., McGeough, M., Donnelly, P., Herity, N., \& Fitzsimons, D. (2014). 'I am still a bit unsure how much of a heart attack it really was!' Patients presenting with non ST elevation myocardial infarction lack understanding about their illness and have less motivation for secondary prevention.

European Journal of Cardiovascular Nursing,13(3),270-276.

https://doi.org/10.1177/1474515113491649

Eldh, A. C., Ehnfors, M., \& Ekman, I. (2004). The phenomena of participation and non-participation in health care-experiences of patients attending a nurse-led clinic for chronic heart failure. European Journal of Cardiovascular Nursing, 3(3), 239-246. https://doi.org/10.1016/j.e jcnurse.2004.05.001

Fålun, N., Fridlund, B., Schaufel, M. A., Schei, E., \& Norekvål, T. M. (2016). Patients' goals, resources and barriers to future change: A qualitative study of patient reflections at hospital discharge after myocardial infarction. European Journal of Cardiovascular Nursing, 15(7), 495-503. https://doi.org/10.1177/1474515115614712

Fors, A., Dudas, K., \& Ekman, I. (2014). Life is lived forwards and under- stood backwards-Experiences of being affected by acute coronary syndrome: A narrative analysis. International Journal of Nursing Studies, 51(3), 430-437. https://doi.org/10.1016/j.ijnurstu.2013.06.012

Grbich, C. (2012). Qualitative data analysis: An introduction. London: Sage.

Grovatsmark, R. E. S., Digre, T., Sneeggen, S., Karlsaune, H., \& Bønaa, K.H. (2017). Norsk hjerteinfarktregister Årsrapport 2016 [The Norwegian Myocardial Infarction Register (NORMI) annual report 2016]. Trond- heim, Norway: St. Olavs Hospital.

Hagen, T. P., Häkkinen, U., Belicza, E., Fatore, G., \& Goude, F. (2015). Acute myocardial infarction, use of percutaneous coronary intervention and mortality: A comparative effectiveness analysis covering seven European countries. Health Economics, 24(S2), 88-101. https://doi.org/10.1002/hec.3263

Höglund, A. T., Winblad, U., Arnetz, B., \& Arnetz, J. E. (2010). Patient participation during hospitalization for myocardial infarction: Perceptions among patients and personnel. Scandinavian Journal of Caring 
Post-print version of the paper by Bårdsgjerde et al. in J Adv Nurs. 2019;00:1-11 . https://doi.org/10.1111/jan13931

Sciences, 24(3), 482-489. https://doi.org/10.1111/j.1471-6712.2009. 00738.x

IHI. (2018a). Person- and family-centered care institute for healthcare improvement. IHI. Retrieved from http://www.ihi.org/Topics/PFCC/Pa ges/Overview.aspx

IHI.(2018b). “What matters” Institute for Healthcare Improvement. Retrieved from http://www.ihi.org/Topics/WhatMatters/Pages/defa ult.aspx

Jelinek, M. V., Thompson, D. R., Ski, C., Bunker, S., \& Vale, M. J. (2015). 40 years of cardiac rehabilitation and secondary prevention in post- cardiac ischaemic patients. Are we still in the wilderness? International Journal of Cardiology, 179, 153-159.https://doi.org/10.1016/j.ij card.2014.10.154

Junehag, L., Asplund, K., \& Svedlund, M. (2014). A qualitative study: Per- ceptions of the psychosocial consequences and access to support after an acute myocardial infarction. Intensive and Critical Care Nurs- ing, 30(1), 22-30. https://doi.org/10.1016/j.iccn.2013.07.002

Kähkönen, O., Kankkunen, P., Saaranen, T., Miettinen, H., Kyngäs, H., \& Lamidi, M. L. (2015). Motivation is a crucial factor for adherence to a healthy lifestyle among people with coronary heart disease after percutaneous coronary intervention. Journal of Advanced Nursing, 71(10), 2364-2373. https://doi.org/10.1111/jan.12708

Kotseva, K., Wood, D., De Bacquer, D., De Backer, G., Rydén, L., Jen- nings, C., ... Castro Conde, A. (2016). EUROASPIRE IV: A European Society of Cardiology survey on the lifestyle, risk factor and thera- peutic management of coronary patients from 24 European countries. European Journal of Preventive Cardiology, 23(6), 636-648. https:// doi.org/10.1177/2047487315569401

Kvale, S., \& Brinkmann, S. (2009). Det kvalitative forskningsintervju [Inter-View: Learning the Craft of Qualitative Research Interviewing]. Oslo: Gyldendal akademisk.

Larsson, I. E., Sahlsten, M. J., Sjöström, B., Lindencrona, C. S., \& Plos, K. A. (2007). Patient participation in nursing care from a patient perspective: A Grounded Theory study. Scandinavian Journal of Caring Sciences, 21(3), 313-320.https://doi.org/10.1111/j.1471-6712.2007.00471.x

Lincoln, Y. S., \& Guba, E. G. (1985). Establishing trustworthiness. In Y. Lincoln \& E. Guba (Eds.), Naturalistic inquiry (pp. 289-330). Beverly Hills, CA: Sage.

Ministry of Health and Care Services. (1999). Lov om pasient- og bruker-rettigheter [Act related to patient's rights]. Oslo: Helse- og omsorgsdepartementet [Ministry of Health and Care Services (HOD)].

Oterhals, K., Hanestad, B. R., Eide, G. E., \& Hanssen, T. A. (2006). The relationship between in-hospital information and patient satisfaction after acute myocardial infarction. European Journal of 
Post-print version of the paper by Bårdsgjerde et al. in J Adv Nurs. 2019;00:1-11 . https://doi.org/10.1111/jan13931

Cardiovascular Nursing, 5(4), 303-310. https://doi.org/10.1016/j.ejcnurse.2006.01.004

Piepoli, M. F., Corra, U., Benzer, W., Bjarnason-Wehrens, B., Dendale, P., Gaita, D., ... Zwisler, A.-D. O. (2010). Secondary prevention through cardiac rehabilitation: From knowledge to implementation. A position paper from the Cardiac Rehabilitation Section of the European Asso- ciation of Cardiovascular Prevention and Rehabilitation. European Journal of Cardiovascular Prevention \& Rehabilitation, 17(1), 1-17. https://doi.org/10.1097/HJR.0b013e3283313592

Piepoli, M. F., Corrà, U., Dendale, P., Frederix, I., Prescott, E., Schmid, J. P., ... Giannuzzi, P. (2016). Challenges in secondary prevention after acute myocardial infarction: A call for action. European Journal of Preventive Cardiology, 23(18), 1994-2006. https://doi.org/10.1177/2047487316663873

Polit, D. F., \& Beck, C. T. (2012). Nursing research: Generating and assessing evidence for nursing practice. Philadelphia, PA: Wolters Kluwer Health.

Radcliffe, E. L., Harding, G., Rothman, M. T., \& Feder, G. S. (2009). 'It got right to the spot' The patient experience of primary angioplasty: A qualitative study. European Journal of Cardiovascular Nursing, 8(3), 216-222.https://doi.org/10.1016/j.ejcnurse.2009.02.001

Report No. 47 (2008-2009) (2008). The coordination reform proper treatment - at the right place and right time. Oslo: Norwegian Ministry of Health and Care Services.

Roffi, M., Patrono, C., Collet, J. P., Mueller, C., Valgimigli, M., Andreotti, F., ... European Society of Cardiology Scientific Document Group. (2016). 2015 ESC Guidelines for the management of acute coronary syndromes in patients presenting without persistent ST-segment elevation: Task Force for the Management of Acute Coronary Syndromes in Patients Presenting without Persistent ST-Segment Elevation of the European Society of Cardiology (ESC). European Heart Journal, 37(3), 267-315. https://doi.org/10.1093/eurheartj/ehv320

Ruano-Ravina, A., Pena-Gil, C., Abu-Assi, E., Raposeiras, S., van't Hof, A.,Meindersma, E., ... GonzálezJuanatey, J. R. (2016). Participation and adherence to cardiac rehabilitation programs. A systematic review. International Journal of Cardiology, 223, 436-443. https://doi.org/ 10.1016/j.ijcard.2016.08.120

Sahlsten, M. J. M., Larsson, I. E., Plos, K. A. E., \& Lindencrona, C. S. C. (2005). Hindrance for patient participation in nursing care. Scandinavian Journal of Caring Sciences, 19(3), 223-229. https://doi.org/ 10.1111/j.1471-6712.2005.00336.x

Sahlsten, M. J., Larsson, I. E., Sjöström, B., \& Plos, K. A. (2008) An analysis of the concept of patient participation. Nursing Forum, 43, 2-11, Wiley Online Library.https://doi.org/10.1111/j.1744- 
Post-print version of the paper by Bårdsgjerde et al. in J Adv Nurs. 2019;00:1-11 . https://doi.org/10.1111/jan13931

6198.2008.00090.X

Salminen-Tuomaala, M., Åstedt-Kurki, P., Rekiaro, M., \& Paavilainen, E. (2012). Coping experiences: A pathway towards different coping orientations four and twelve months after myocardial infarction-a grounded theory approach. Nursing Research and Practice, 2012, 674783.

Sampson, F., O'Cathain, A., \& Goodacre, S. (2009). Feeling fixed and its contribution to patient satisfaction with primary angioplasty: A qualitative study. European Journal of Cardiovascular Nursing, 8(2), 85-90. https://doi.org/10.1016/j.ejcnurse.2008.07.003

Sarbin, T. R. (1986). The narrative as a root metaphor for psychology. In T. R. Sarbin (Ed.), Narrative psychology: The storied nature of human conduct (pp. 3-21). New York: Praeger.

Shimada, Y. J., \& Scirica, B. M. (2015). Long-term management and unmet needs after an acute coronary syndrome event. American Journal of Cardiology, 115(5), 29A-35A. https://doi.org/10.1016/j.amjcard.2015. 01.005

Svavarsdóttir, M. H., Sigurdardottir, A. K., \& Steinsbekk, A. (2016). What is a good educator? A qualitative study on the perspective of individuals with coronary heart disease. European Journal of Cardiovascular Nursing, 15(7), 513-521. https://doi.org/10.1177/1474515115618569

Tanguay, A., Dallaire, R., Hébert, D., Bégin, F., \& Fleet, R. (2015). Rural patient access to primary percutaneous coronary intervention centers is improved by a novel integrated telemedicine prehospital system. The Journal of emergency medicine, 49(5), 657-664. https://doi.org/ 10.1016/j.jemermed.2015.05.009

Task Force on the management of ST segment elevation acute myocardial infarction of the European Society of Cardiology; Steg, P. G., James, S. K., Atar, D., Badano, L. P., Blomstrom-Lundqvist, C., ... Zahger, D. (2012). ESC guidelines for the management of acute myocardial infarction in patients presenting with STsegment elevation. European Heart Journal, 33(20), 2569-2619.

Thompson, A. G. H. (2007). The meaning of patient involvement and participation in health care consultations: A taxonomy. Social Science \& Medicine, 64(6), 1297-1310. https://doi.org/10.1016/j.socscimed.2006.11.002

Tobiano, G., Marshall, A., Bucknall, T., \& Chaboyer, W. (2015). Patient participation in nursing care on medical wards: An integrative review. International Journal of Nursing Studies, 52(6), 1107-1120. https:// doi.org/10.1016/j.ijnurstu.2015.02.010

Townsend, N., Nichols, M., Scarborough, P., \& Rayner, M. (2015). Cardio- vascular disease in Europeepidemiological update 2015. European Heart Journal, 36(40), 2696-2705. https://doi.org/10.1093/eurheartj/ 
Post-print version of the paper by Bårdsgjerde et al. in J Adv Nurs. 2019;00:1-11 . https://doi.org/10.1111/jan13931

ehv428

Vahdat, S., Hamzehgardeshi, L., Hessam, S., \& Hamzehgardeshi, Z. (2014). Patient involvement in health care decision making: A review. Iranian Red Crescent Medical Journal, 16(1), e12454.

Valaker, I., Norekvål, T. M., Rảholm, M.-B., Nordrehaug, J. E., Rotevatn, S.,\& Fridlund, B. (2017). Continuity of care after percutaneous coronary intervention: The patient's perspective across secondary and primary care settings. European Journal of Cardiovascular Nursing, 16(5), 444-452.

https://doi.org/10.1177/1474515117690298

World Health Organization. (2017). Cardiovascular diseases (CVDs) Fact sheet. WHO. Retrieved from http://www.who.int/news-room/fact- sheets/detail/cardiovascular-diseases-(cvds)

How to cite this article: Bårdsgjerde EK, Kvangarsnes $\mathrm{M}$, Landstad B, Nylenna M, Hole T. Patients' narratives of their patient participation in the myocardial infarction pathway. J Adv Nurs. 201 9;00:1-11. https://doi.org/10.1111/jan.13931 